\title{
Article
}

\section{The Chitinolytic Activities of Streptomyces sp. TH-11}

\section{Kim-Chi Hoang ${ }^{1}$, Tzu-Hsuan Lai ${ }^{2}$, Chung-Sheng Lin ${ }^{3}$, Ying-Tsong Chen ${ }^{4,5, \dagger}$ and Chun-Yi Liau ${ }^{2, \dagger}, *$}

1 General Education Center, Ta Hwa Institute of Technology, HsinChu 307, Taiwan;

E-Mail: chi@thit.edu.tw

2 Departments of Bioengineering, Tatung University, Taipei 104, Taiwan;

E-Mail: sonic_9001@hotmail.com

3 School of Medicine, Chung Shan Medical University and Department of Internal Medicine, Chung Shan Medical University Hospital, TaiChung City 402, Taiwan; E-Mail: lcs@ csmu.edu.tw

4 Institute of Genomics and Bioinformatics, National Chung Hsin University, TaiChung City 402, Taiwan; E-Mail: onion@nchu.edu.tw

5 Division of Molecular and Genomics Medicine, National Health Research Institutes, Miaoli 350, Taiwan

$\dagger$ These authors contributed equally to this manuscript.

* Author to whom correspondence should be addressed; E-Mail: chunyi @ttu.edu.tw;

Tel.: +886-2-25925252-3315-31; Fax: +886-2-25854735.

Received: 28 October 2010; in revised form: 10 December 2010 / Accepted: 18 December 2010 / Published: 27 December 2010

\begin{abstract}
Chitin is an abundant biopolymer composed of units of $N$-acetyl-D-glucosamine linked by $\beta-1,4$ glycosidic bonds. Chitin is the main component of the shells of mollusks, the cell wall of fungi and yeast and of the exoskeleton of crustaceans and insects. The degradation of chitin is catalyzed by chitinases that occur in a wide range of organisms. Among them, the chitinases from microorganisms are extremely important for the degradation and recycling of the carbon and nitrogen trapped in the large amount of insoluble chitin in nature. Streptomyces sp. TH-11 was isolated from the sediment of the Tou-Chien River, Taiwan. The chitinolytic enzyme activities were detected using a rapid in-gel detection method from the cell-free preparation of the culture medium of TH-11. The chitinolytic enzyme activity during prolonged liquid culturing was also analyzed by direct measurement of the chitin consumption. Decomposition of the
\end{abstract}


exoskeleton of shrimps was demonstrated using electron microscopy and atomic force microscopy.

Keywords: chitin; Streptomyces; chitinase

\section{Introduction}

Chitin is a linear polysaccharide made of $\beta-1,4$ linked $N$-acetyl-D-glucosamine (GlcNAc). More than $1 \times 10^{10}$ to $1 \times 10^{12}$ tones of chitin are produced annually in terrestrial and marine habitats, making it the second most abundant polysaccharide in nature, after cellulose. Chitin is insoluble in water and exists with different degree of acetylation, different molecular sizes (up to several MDa), and can associate with other organic and inorganic compounds. It occurs mainly as a structural component in the cell walls of fungi and yeast and the exoskeletons of insects and crustaceans. Chitosans are components derived by enzymatic deacetylation of chitin and are found in the cell walls of certain fungi [1].

In a previous study, we reported a simple and rapid detection technique for in-gel glycol chitosan activity staining [2]. The samples containing chitinolytic enzymes were prepared with $\beta$-mercaptoethanol-free loading buffer and separated by electrophoresis utilizing 12\% SDS-PAGE containing $0.01 \%(\mathrm{w} / \mathrm{v})$ glycol chitosan. Clearance of the embedded glycol chitosan by the enzymes can be detected after electrophoresis by a modified Coomassie Brilliant Blue G 250 staining [3].

Streptomycetes are soil-dwelling mycelial bacteria that produce a large number of secreted proteins and many secondary metabolites, including important antibiotics. Chitin is a major nutrient source for many streptomycetes, and these microorganisms have developed complex extracellular systems for chitin utilization [4]. Analyses of the genomes of various Streptomyces strains have revealed many chitinase genes, potentially enabling them to hydrolyze the diverse chitin types they encounter. For example, analysis of the genomic sequence of a Streptomyces coelicolor strain revealed as many as 13 putative chitinases [5,6]. Nowadays, chitinases have been purified from various Streptomyces strains, but detailed studies on the enzymes that degrade chitin form exoskeletons or fungal walls are, however, scarce.

Streptomyces sp. TH-11 was isolated from the sediment of the Tou-Chien River in Taiwan in a previous study [7]. A total of 305 isolates from different regions of the river were screened in the study. Twelve strains were found to be capable of degrading poly( $\beta$-hydroxybutyrate) (PHB), poly( $\varepsilon$-caprolactone) (PCL) and poly(ethylene succinate) (PES) and TH-11 is one of the best degraders [7,8]. According to $16 \mathrm{~S}$ rRNA sequence comparison, TH-11 shows $99 \%$ sequence identity with Streptomyces viridochromogenes, a strain that produces several chitinolytic enzymes. Since chitin is abundant in the natural habitat of TH-11, the chitinolytic activities of this strain were analyzed using chitin powder, glycol chitosan and raw shrimp shells in the present study. 


\section{Results and Discussion}

\subsection{Degradation of Chitin Powder by Streptomyces sp. TH-11}

Streptomyces sp. TH-11 was cultured with degradation media containing $0.1 \%(\mathrm{w} / \mathrm{v})$ chitin powder (Wako Pure Chem., Japan) with vigor agitation at $30{ }^{\circ} \mathrm{C}$. The total dry weight of the culture was measured over 30 days (Figure 1a). Since many of the hydrolytic activities such as esterase or PES depolymerase of Streptomyces were reported to be inducible by addition of proteins such as gelatin to the culture media, the effect of gelatin addition was also measured. The degradation of chitin powder, demonstrated by the decline of total dry weight, was not enhanced by gelatin addition (Figure 1a). The cell growth, which is enhanced by gelatin addition, may have contributed to the increase of total dry weight at the early stage of culturing. It has been shown in a PES depolymerase study that prolonged culturing resulted in an increase of $\mathrm{pH}$ [8]. In the present chitin powder degradation test, a similar increasing of $\mathrm{pH}$ value of the culture media is also observed during prolonged culturing (Figure $1 \mathrm{~b}$ ). Specific chitinolytic activity (U/mg total protein) in the medium produced by Streptomyces sp. TH-11 during the 30 days of the chitin powder degradation test was also tested after removal of cells and insoluble material by centrifugation and filtration. The highest specific chitinolytic activity ( $1100 \mathrm{U} / \mathrm{mg}$ total protein) was detected at day 12 to16. It had also been reported that up to eight days of incubation is necessary for Streptomyces strains to reach maximum chitinase activity production in optimized liquid culture conditions [9].

Figure 1. (a) Chitin powder degradation test (30 days). The dry-weight (mg) of the culture was measured after inoculation. Decrease of the total dry weight for samples with (solid square) or without (open square) gelatin $(1 \mathrm{mg} / \mathrm{mL})$; (b) Change of $\mathrm{pH}$ value of the culture media during the chitin powder degradation test. Samples cultured with or without gelatin $(1 \mathrm{mg} / \mathrm{mL})$ are shown by solid squares and open squares, respectively.

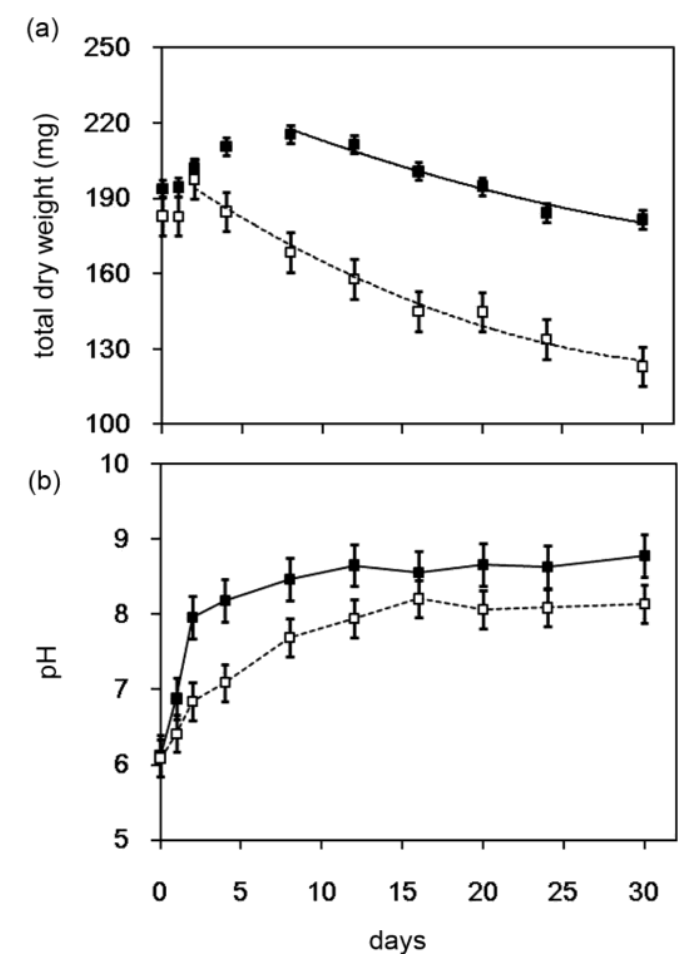




\subsection{In-gel Activity Staining of Chitinolytic Enzymes from Streptomyces sp. TH-11}

Culture media from the chitin powder degradation experiments were also collected by removal of the cells and other insoluble substances, and subjected to in-gel chitinolytic activity staining using a previously published method [3]. The degradation of embedded glycol chitosan (Sigma-Aldrich, MO, U.S.) resulted in clear zones visualized by Coomassie Brilliant Blue G 250 (Figure 2). A clear zone corresponding to a MW of about $29 \mathrm{kDa}$ was observed and appeared to be expressed in highest yield at day $12-16$. This is consistent to the specific chitinolytic activity of the culture medium measured by reducing end production, which is also highest at day $12-16$.

Chitinases of various molecular weights have been identified in various Streptomyces strains [10]. These including a $20 \mathrm{kDa}$ chitinase from Streptomyces sp. M-20, $28 \mathrm{kDa}, 25 \mathrm{kDa}$, and $45 \mathrm{kDa}$ from Streptomyces sp. NK 1057, $45 \mathrm{kDa}$ and $45 \mathrm{kDa}$ from $S$. albovinaceus $\mathrm{S}-22,45 \mathrm{kDa}$ from Streptomyces sp. ANU 6277, and 49 kDa from S. griseus HUT 6037 [11,12]. Based on sequence similarity, chitinases are classified into two families: 18 and 19. Chitinases belong to family 18 are widespread among a variety of organisms, but those of family 19 are found almost only in higher plants. For Actinobacteria, the distribution of family 19 chitinase was systematically studied, and it was suggested that that family 19 chitinases of Streptomyces species were acquired from plants by horizontal gene transfer [13]. Genomics analyses on Streptomyces coelicolor A3(2) genome have identified 11 family 18 and two family 19 chitinases [6]. Among these, a $29 \mathrm{kDa}$ family 19 chitinase Chi19F was identified with high activity toward glycol chitin and soluble chitin [6]. Identification of the glycol chitosan hydrolyzing activity at $29 \mathrm{kDa}$ in our study makes an addition to this repertoire. Further enzymatic studies are, however, necessary to characterize the $29 \mathrm{kDa}$ chitinase.

Figure 2. Detection of the chitinolytic activity in the culture medium of TH-11 during the chitin-powder degradation test. The cell-free samples prepared from the culture media were separated in a glycol chitosan-embedded SDS-PAGE and then stained using a previously reported method [3]. The $29 \mathrm{kDa}$ clear zones, which appeared to be most obvious at day 16, are indicated.

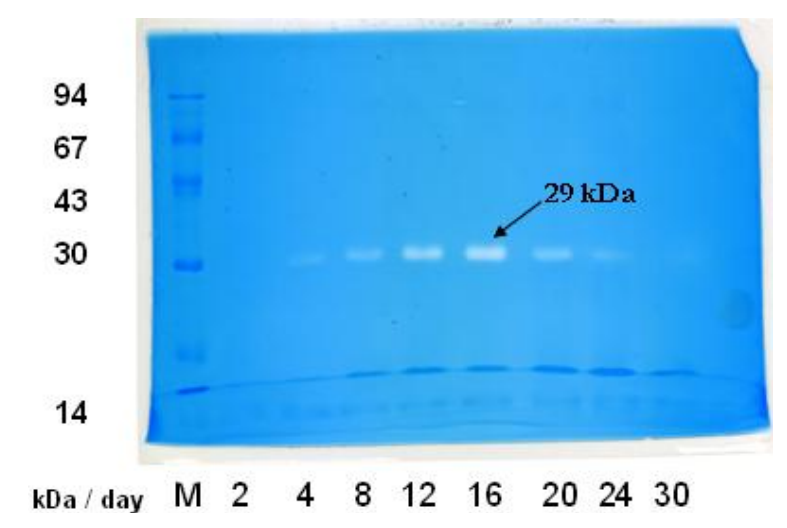

\subsection{Decomposition of Shrimp Shells by Streptomyces $s p$. TH-11}

It is estimated that chitin composes $20 \%$ of raw shrimp shells in weight [14]. To test the degradation of shrimp shells by Streptomyces sp. TH-11, the bacteria were cultured with degradation media containing $0.1 \%(\mathrm{w} / \mathrm{v})$ dry and grinded shrimp shells with vigorous agitation at $30{ }^{\circ} \mathrm{C}$. The total dry 
weight of the bacteria in the culture medium was measured over 21 days (Figure 3a). The shrimp shells were removed from the medium and the dry weights were measured to monitor the dissipation (Figure 3b). In 20 days, about half of the insoluble shrimp shells were diminished. Addition of $1 \mathrm{mg} / \mathrm{mL}$ gelatin to the media did not enhance the dissipation of shrimp shells by TH-11, but supported better cell growth.

Figure 3. (a) Growth of Streptomyces sp. TH-11 on media containing ground shrimp shells; (b) Dissipation of shrimp shells monitored by direct weight measurement. Samples cultured with or without gelatin $(1 \mathrm{mg} / \mathrm{mL})$ are shown by solid squares and open squares, respectively.

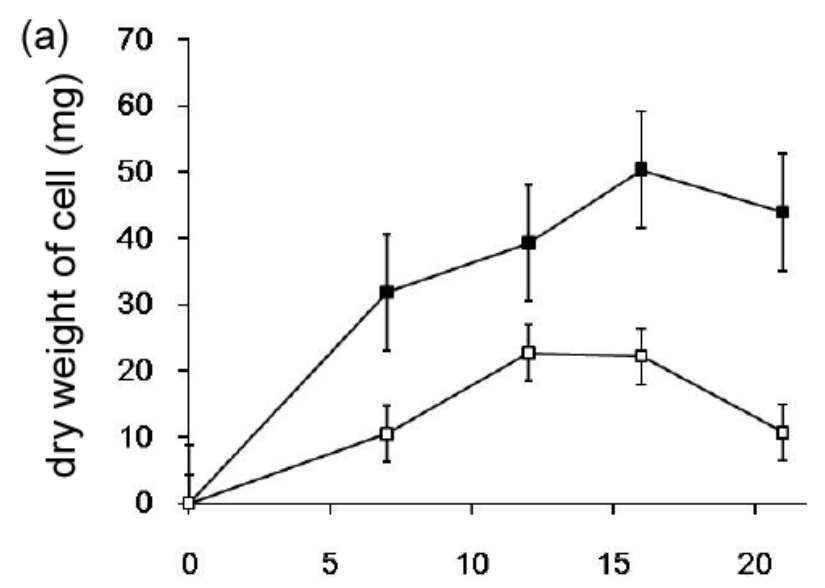

(b) days

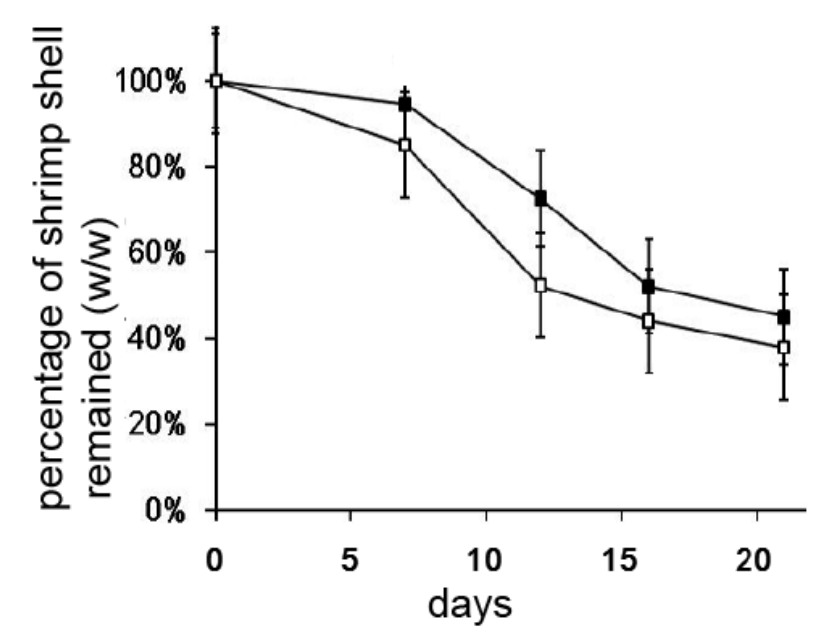

\subsection{Decomposition of Shrimp Shells Visualized by SEM and AFM}

Atomic force microscopy (AFM) was utilized to detect the changes on the surface structure of the shrimp shells in the decomposition experiment. A comparison between day 0 and day 7 is shown (Figure 4a, b). The decomposition of shrimp shells was also demonstrated by scanning electron microscopy (SEM) at day 0, day 7, day 12 and day 16 (Figure 4c, d, e, f). Compared with the original surface at day 0, break down of the shrimp shell is apparent after incubation with Streptomyces sp. TH-11. Streptomycetes contain many chitinase genes to hydrolyze diverse chitin types with different molecular sizes, degree of acetylation, and associated organic/inorganic compounds. The 
aforementioned chitinolytic activity detected at $29 \mathrm{kDa}$, presumably a family 19 chitinase that is active on a soluble substrate, may not be the enzyme responsible for the decomposition of shrimp shells since family 19 chitinases are not active toward crystalline substrates [6]. On the other hand, some of the chitinases may not have sufficient activity toward glycol chitosan and may not appear in the zymogram shown in Figure 2.

Figure 4. (a) The shrimp shells at day 0 visualized by atomic force microscopy (AFM); (b) The shrimp shells after 7 days of incubation with TH-11 visualized by AFM; (c) Scanning electron microscopy (SEM) of the shrimp shells at day 0; (d) SEM on the shrimp shells at day 7; (e) SEM on the shrimp shells at day 12; (f) SEM on the shrimp shells at day 16. Panels (c)-(f): magnification is $5000 \times$.

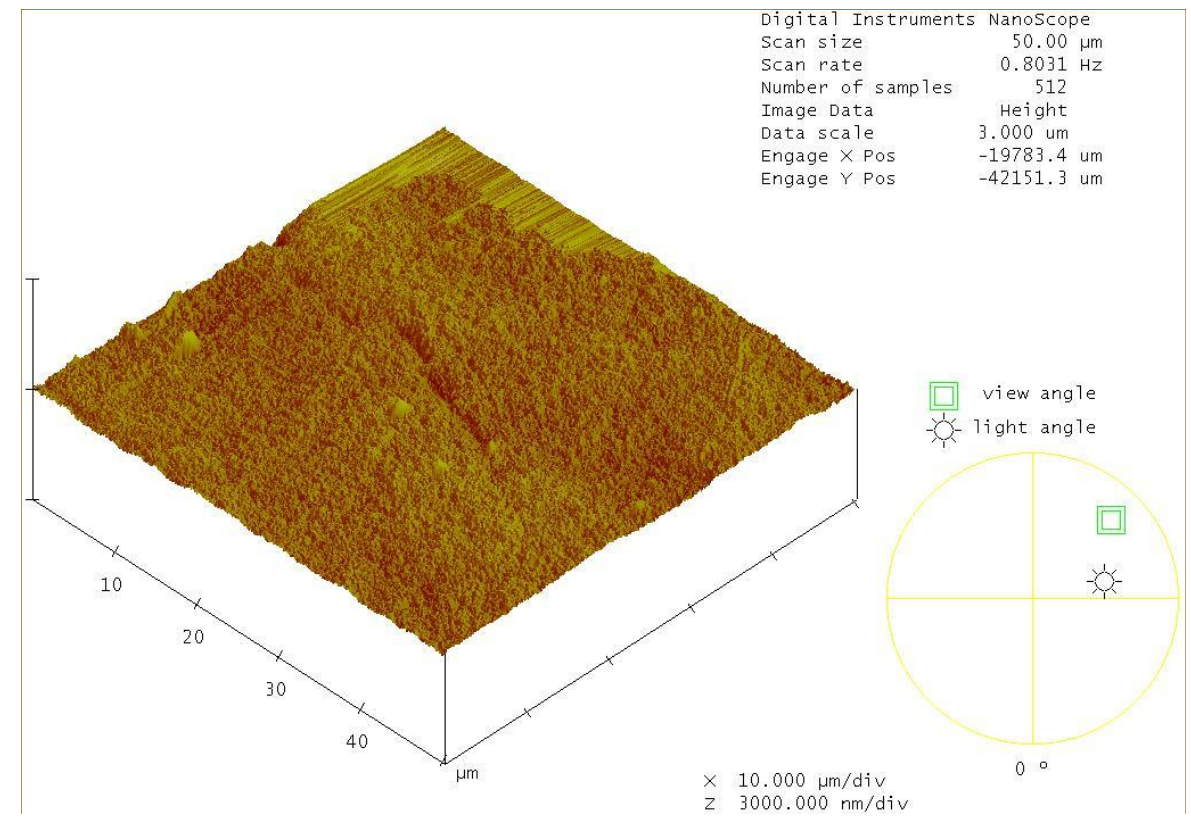

(a)

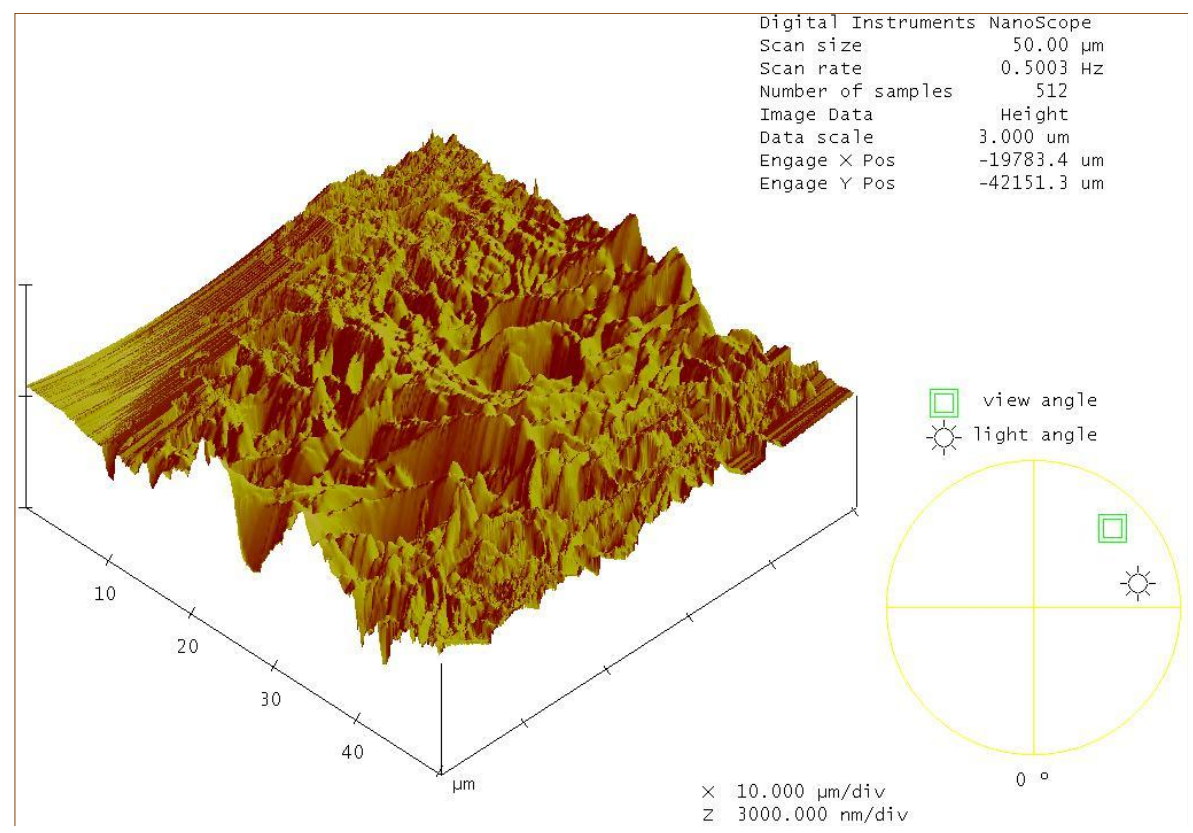

(b) 
Figure 4. Cont.

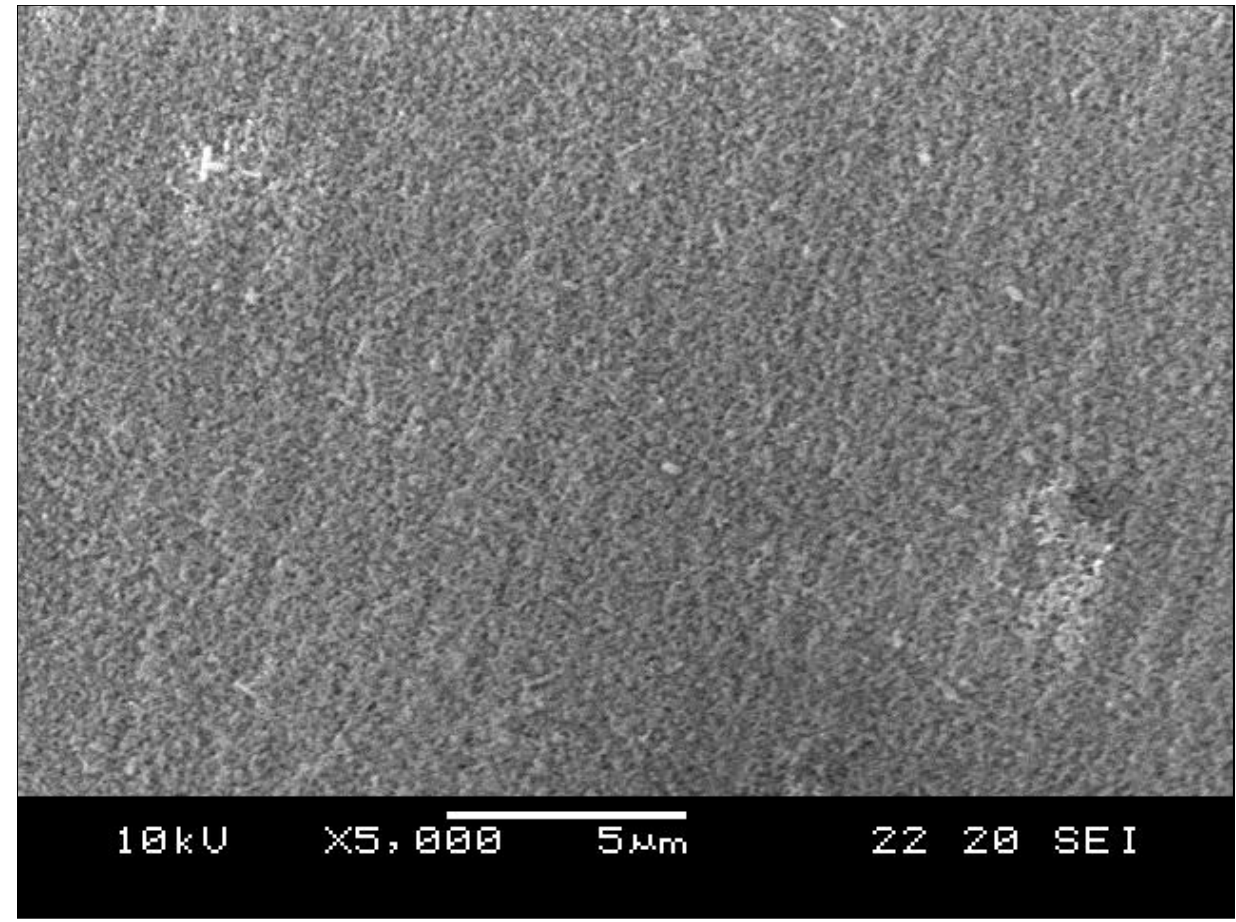

(c)

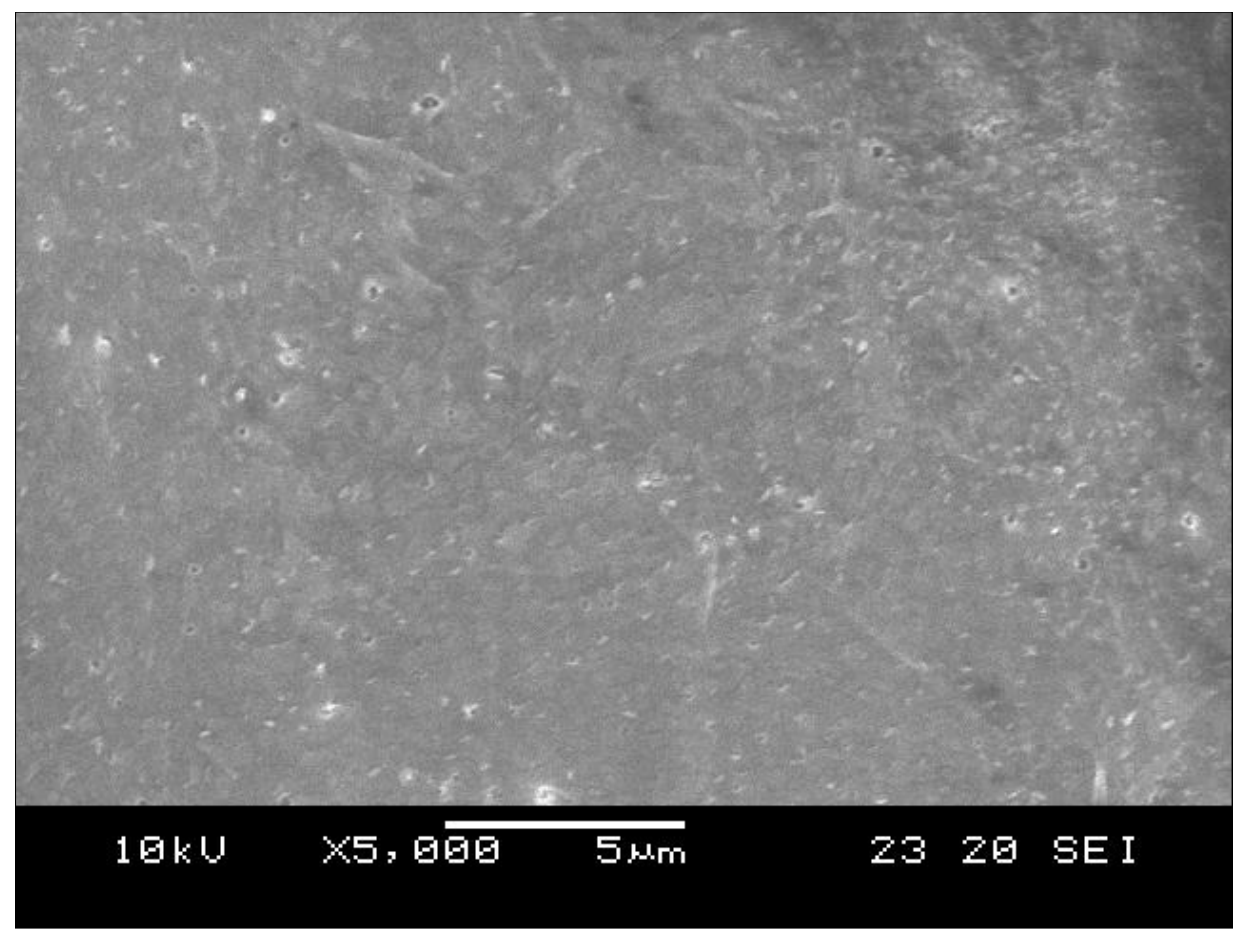

(d) 
Figure 4. Cont.

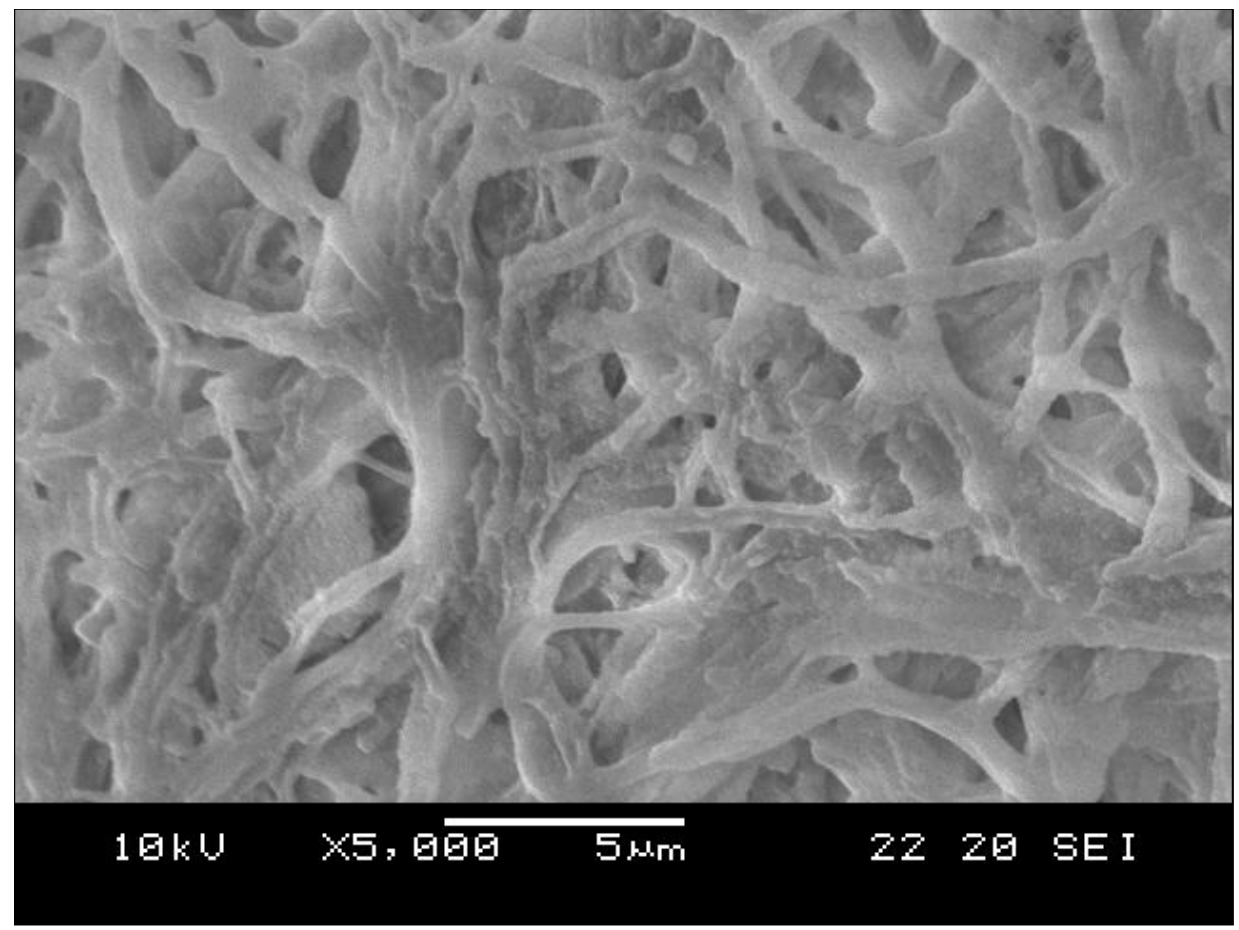

(e)

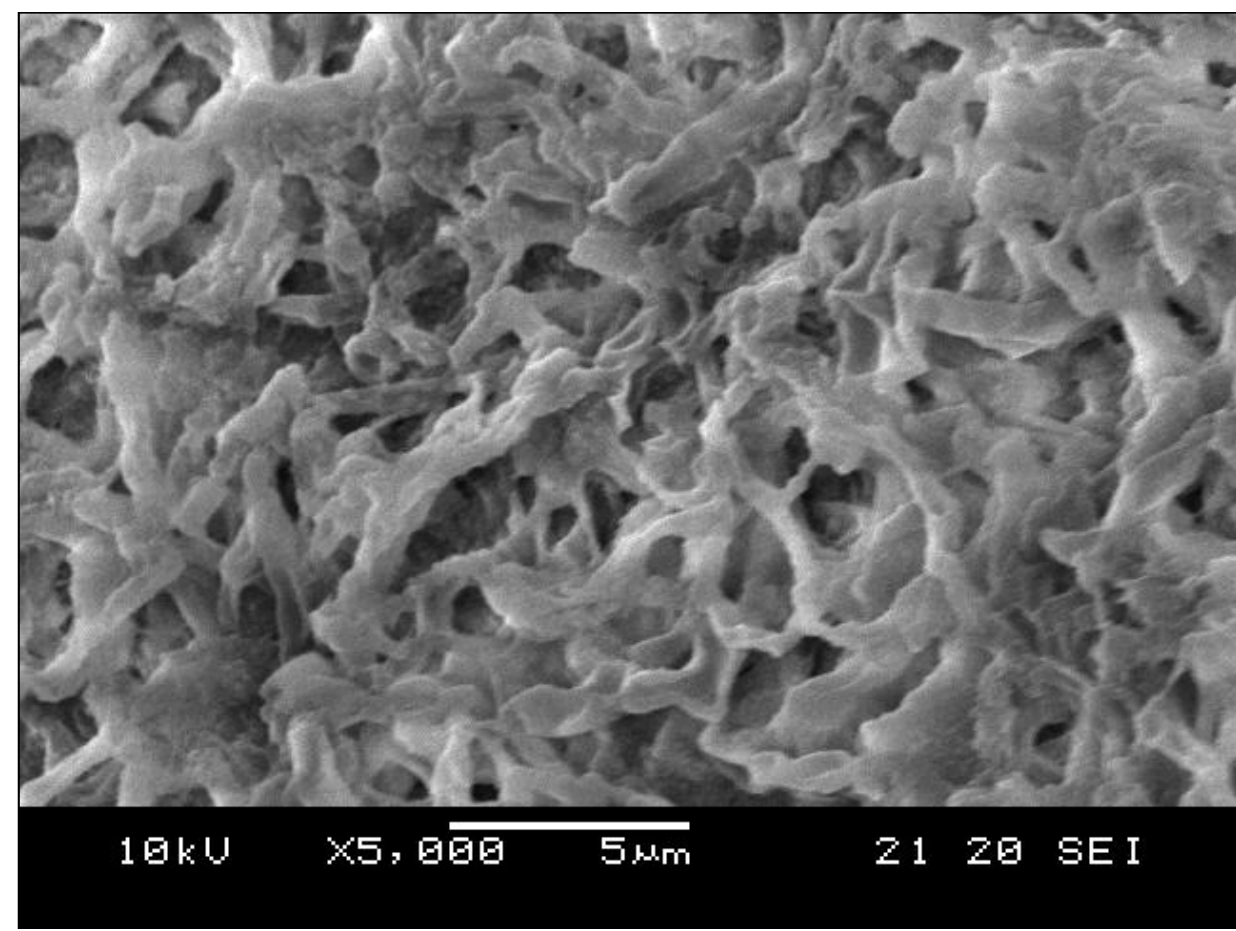

(f)

\section{Experimental Section}

Streptomyces sp. TH-11 was isolated from soil samples collected from the sediment of Tou-Chien River, Taiwan [7]. Streptomyces was cultured in modified Starch-Casein medium (Starch $4 \mathrm{~g}$, Casein $0.12 \mathrm{~g}, \mathrm{KNO}_{3} 1.6 \mathrm{~g}, \mathrm{NaCl} 1.6 \mathrm{~g}, \mathrm{~K}_{2} \mathrm{HPO}_{4} 1.6 \mathrm{~g}, \mathrm{MgSO}_{4} \cdot 7 \mathrm{H}_{2} \mathrm{O} 40 \mathrm{mg}, \mathrm{CaCO}_{3} 16 \mathrm{mg}$, $\mathrm{FeSO}_{4} \cdot 7 \mathrm{H}_{2} \mathrm{O} 8 \mathrm{mg}$ in $1000 \mathrm{~mL}$ water, $\mathrm{pH}$ 7) containing $50 \mu \mathrm{g} / \mathrm{mL}$ cycloheximide. Separation and 
detection of chitinolytic enzymes in glycol chitosan-containing polyacrylamide gel by electrophoresis and modified Coomassie Brilliant Blue G 250 staining were performed as previously described [3]. Degradation media was prepared by mixing $1 \mathrm{~g}$ of chitin powder (Wako Pure Chem., Japan) in $1 \mathrm{~L}$ medium containing 0.1 g yeast extract, $10 \mathrm{mg} \mathrm{FeSO} \cdot 7 \mathrm{H}_{2} \mathrm{O}, 0.2 \mathrm{~g} \mathrm{MgSO}_{4} \cdot 7 \mathrm{H}_{2} \mathrm{O}, 1 \mathrm{~g}\left(\mathrm{NH}_{4}\right)_{2} \mathrm{SO}_{4}, 20 \mathrm{mg}$ $\mathrm{CaCl}_{2} \cdot 2 \mathrm{H}_{2} \mathrm{O}, 0.1 \mathrm{~g} \mathrm{NaCl}, 0.5 \mathrm{mg} \mathrm{Na} 2 \mathrm{MoO}_{4} \cdot 2 \mathrm{H}_{2} \mathrm{O}, 0.5 \mathrm{mg} \mathrm{Na} \mathrm{WO}_{4} \cdot 2 \mathrm{H}_{2} \mathrm{O}, 0.6 \mathrm{mg} \mathrm{MnSO} \mathrm{M}_{4} \cdot \mathrm{H}_{2} \mathrm{O}$, and detergent $\left(\mathrm{CH}_{3}\left(\mathrm{CH}_{2}\right)_{\mathrm{n}} \mathrm{COONa}, n=6 \sim 14\right.$, Nice Co., Taiwan). Weight of the cells and remaining chitin in the liquid media after prolonged incubation were performed by direct measurement of the dry weight.

Chitinolytic activity was determined by measuring the reducing end group produced from glycol chitosan (Sigma-Aldrich, MO, U.S). The reaction mixture, consisting of $100 \mu \mathrm{L}$ of enzyme solution, $36 \mu \mathrm{L}$ of $25 \mathrm{mg} / \mathrm{mL}$ glycol chitosan (a final concentration of $1 \mathrm{mg} / \mathrm{mL}$ ) and $764 \mu \mathrm{L}$ of $0.1 \mathrm{M}$ sodium acetate buffer, $\mathrm{pH} 5.0$, was incubated at $37{ }^{\circ} \mathrm{C}$ for $30 \mathrm{~min}$, and then the reaction was terminated by heating in boiling water for $15 \mathrm{~min}$. The reducing end group produced was measured colorimetrically by potassium ferricyanide assay [15]: the reaction solution was mixed with $1.0 \mathrm{~mL}$ potassium ferricyanide reagent, heated in boiling water for $15 \mathrm{~min}$, and then subjected to spectrophotometry measurement at $410 \mathrm{~nm}$. One unit of chitinase activity was defined as capable of releasing reducing ends corresponding to $1 \mu \mathrm{g}$ of GlcNAc from glycol chitosan in an hour. Pacific white shrimp (Litopenaeus vannamei) was purchased from a local market. After boiling in water, the shrimp shell was peeled off, sun-dried and crushed.

Atomic force microscopy was performed using Dimension 3100 AFM with NS3a controller (Digital Instruments/Veeco Inc., Santa Barbara, CA, U.S.). Scanning electron microscopy was performed using a Hitachi S-570 (Hitachi, Japan).

\section{Conclusions}

Chitinolytic systems of Streptomyces are usually composed of a diversity of enzymes with different specificities. In this study, chitinolytic activities of Streptomyces sp. TH-11 were demonstrated using three different substrates: chitin powder, glycol chitosan, and shrimp shells. Activity staining on the cell-free culture medium indicated an activity zone on embedded glycol chitosan at an approximate molecular weight of $29 \mathrm{kDa}$. The decomposition effects of shrimp shells by TH-11 were apparent as visualized using SEM and AFM, in addition to the reduction in shrimp shell mass. Taken together, as one of the best degraders we screened from the river sediment with depolymerase activities, the strain is also capable of decomposing different chitin substrates including $\beta$-chitin (crystalline powder), deacetylated chitin (glycol chitosan), and raw shrimp shells, presumably by producing different chitinolytic enzymes.

\section{Acknowledgements}

The study was supported in part by basic research grant B98-S05-017, and B99-S04-030 from Tatung University. A part of this research was funded by National Science Consul, 98-2815-C-036-015-B. The authors are grateful to C.-C. Chiang, from the department of Material Engineering, Tatung University, for assistance with SEM, and M.-S. Yang, from the Instrument Center of Tatung University for assistance with AFM. 


\section{References}

1. Kumar, M.N.; Muzzarelli, R.A.; Muzzarelli, C.; Sashiwa, H.; Domb, A.J. Chitosan chemistry and pharmaceutical perspectives. Chem. Rev. 2004, 104, 6017-6084.

2. Liau, C.Y.; Lin, C.S. Detection of chitinolytic enzymes in Ipomoea batatas leaf extract by activity staining after gel electrophoresis. J. Chin. Chem. Soc. 2008, 55, 678-681.

3. Liau, C.Y.; Lin, C.S. A modified Coomassie Brilliant Blue G 250 staining method for the detection of chitinase activity and molecular weight after polyacrylamide gel electrophoresis, J. Biosci. Bioeng. 2008, 106, 111-113.

4. Chater, K.F.; Biro, S.; Lee, K.J.; Palmer, T.; Schrempf, H. The complex extracellular biology of Streptomyces. FEMS Microbiol. Rev. 2009, 34, 171-198.

5. Bentley, S.D.; Chater, K.F.; Cerdeño-Tárraga, A.M.; Challis, G.L.; Thomson, N.R.; James, K.D.; Harris, D.E.; Quail, M.A.; Kieser, H.; Harper, D.; et al. Complete genome sequence of the model actinomycete Streptomyces coelicolor A3(2). Nature 2002, 417, 141-147.

6. Kawase, T.; Yokokawa, S.; Saito, A.; Fujii, T.; Nikaidou, N.; Miyashita, K.; Watanabe, T. Comparison of Enzymatic and Antifungal Properties between Family 18 and 19 Chitinases from $S$. coelicolor A3(2). Biosci. Biotechnol. Biochem. 2006, 70, 988-998.

7. Hoang, K.C.; Lee, C.Y.; Tseng, M.; Chu, W.C. Polyester-degrading actinomycetes isolated from the Touchien River of Taiwan. World J. Microbiol. Biotechnol. 2007, 23, 201-205.

8. Hoang, K.C.; Lee, C.Y.; Lai, Y.C.; Liau, C.Y. TH-11, a Streptomyces sp. strain that degrades poly(3-hydroxybutyrate) and poly(ethylene succinate). J. Chin. Chem. Soc. 2008, 55, 1214-1220.

9. Nawani, N.N.; Kapadnis, B.P. Optimization of chitinase production using statistics based experimental designs. Process Biochem. 2005, 40, 651-660.

10. Hjort, K.; Bergstrom, M.; Adesina, M.F.; Jansson, J.K.; Smalla, K.; Sjöling, S. Chitinase genes revealed and compared in bacterial isolates, DNA extracts and a metagenomic library from a phytopathogen-suppressive soil. FEMS Microbiol. Ecol. 2010, 71, 197-207.

11. Bhattacharya, D.; Nagpure, A.; Gupta, R.K. Bacterial chitinases: properties and potential. Critical Rev. Biotechnol. 2007, 27, 21-28.

12. Narayana, K.J.P.; Vijayalakshmi, M. Chitinase Production by Streptomyces sp. ANU 6277. Braz. J. Microbiol. 2009, 40, 725-733.

13. Kawase, T.; Saito, A.; Sato, T.; Kanai, R.; Fujii, T.; Nikaidou, N.; Miyashita, K.; Watanabe, T. Distribution and Phylogenetic Analysis of Family 19 Chitinases in Actinobacteria. Appl. Environ. Micorbiol. 2004, 70, 1135-1144.

14. Percot, A.; Viton, C.; Domard, A. Optimization of chitin extraction from shrimp shells. Biomacromolecules 2003, 4, 12-18.

15. Imoto, T.; Yagishita, K. A simple activity measurement of lysozyme. Agric. Biol. Chem. 1971, 35, 1154-1156.

(C) 2010 by the authors; licensee MDPI, Basel, Switzerland. This article is an open access article distributed under the terms and conditions of the Creative Commons Attribution license (http://creativecommons.org/licenses/by/3.0/). 